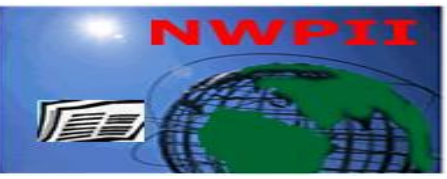

American Journal of

Biomedical Sciences

ISSN: 1937-9080

nwpii.com/ajbms

\title{
Factors Influencing Full Immunization Coverage among under Five Years Children in Mogadishu, Somalia
}

\author{
Mohamed Hayir Tahlil Mohamud*
}

Jazeera University, Mogadishu, Somalia

*Corresponding Author

Mohamed Hayir Tahlil Mohamud

Jazeera University

Mogadishu

Somalia

Tell: +252615445949

Email:xayir070@gmail.com

Received:17 March 2020; | Revised:10 April 2021; | Accepted:01 May 2021

\section{Abstract}

Background: Immunization is amongst the most cost effective public health interventions for reducing childhood morbidity and mortality. However, various reports show that 9 million children die globally due to vaccine-preventable disease, in which a bigger proportion occurred in sub-Saharan Africa with 4.4 million deaths. Therefore, this study aimed to assess barriers for full vaccination coverage among under five years children in Mogadishu, Somalia.

Methods: A community based cross-sectional study was conducted from April to July, 2019 in Mogadishu-Somalia. Two-stage cluster sampling with systematic random sampling was used to select 820 households. Data was collected through structured, interviewer administrator questionnaire. In case more eligible children were found at single selected household, one child was randomly selected and the information related to immunization was obtained from his/her caregiver.

Results: The overall, fully immunized under five years children was found to be $45.2 \%$. Using Multivariate logistic regression models, being a younger caregiver $(\beta=-0.019, \mathrm{P}$-value $=0.042)$, married caregiver $[(\mathrm{AOR}=4.101,95 \% \mathrm{CI}$ : 1.062-15.835, $\mathrm{P}$-value=0.041), Father with Secondary \& above education $(\mathrm{AOR}=1.755,95 \% \mathrm{CI}: 1.161-2.655, \mathrm{P}$-value $=0.008)$, a younger child $(\beta=-0.018, \mathrm{P}$-value $=0.011)$, children from birth order of fifth $\&$ above $(\mathrm{AOR}=1.539,95 \% \mathrm{CI}: 1.011-2.343$, P-value=0.044), high family income $(\beta$ $=0.003$, P-value $=0.000)$, Availability of vaccine at the time of visit to the health centre $(\mathrm{AOR}=6.118,95 \%$ $\mathrm{CI}: 1.931-19.381$, P-value $=0.002)$, affordability of vaccine related Cost (AOR $=1.938,95 \% \mathrm{CI}: 1.230-3.053$, $\mathrm{P}$-value $=0.004)$, Being born at health facility $(\mathrm{AOR}=1.519,95 \% \mathrm{CI}: 1.105-2.088, \mathrm{P}$-value $=0.010)$, caregivers good Knowledge on immunization (AOR $=1.125$, 95\%CI:1.070-1.181, P-value $=0.001$ ), caregivers' good Practice on immunization (AOR=2.756, 95\%CI:2.233-3.402, P-value $=0.001)$ and caregivers' good Perception on immunization $(\mathrm{AOR}=4.976,95 \% \mathrm{CI}: 2.183-11.340, \mathrm{P}$-value $=0.001)$ were found to increase the immunization coverage of the children. 
Conclusion: The result of this study has revealed that the proportion of fully immunized under five children in Mogadishu is very low. Several socio-demographic, health centres related and socio-cultural factors were found to barriers for full immunization coverage. Steps to promote Health education and vaccine availability should be launched.

Keywords: Barriers, full Immunization, Coverage

\section{Introduction}

Immunization is amongst the most cost effective public health interventions for reducing global childhood morbidity and mortality ${ }^{[1]}$. In 1974, World Health Organization (WHO) established the Expanded Program on Immunization (EPI) to ensure that all children get access for vaccination. To synergize EPI, the United Nations General Assembly Special Session (UNGASS) set a goal to ensure full immunization of children under one year at $90 \%$ coverage nationally with at least $80 \%$ coverage in every district by 2010 . Building on this goal, the World Health Assembly endorsed the Global Vaccine Action Plan (GVAP) in 2012 to extend immunization to all children across the globe. GVAP's key targets include achieving and sustaining $90 \%$ national pentavalent coverage and $\geqslant 80 \%$ Penta coverage in every District by $2015^{[2]}$.

When the EPI was initiated in 1974, less than $5 \%$ of children in developing countries were receiving a third dose of diphtheria-tetanuspertussis (DTP-3) and poliomyelitis vaccines in their first year of life ${ }^{[3]}$. A report from WHO revealed that around $60 \%$ of children's who were not reached with routine immunization services are from 10 countries where majority are from subSaharan African countries ${ }^{[4]}$. Routine immunization coverage is assessed by Penta 3 coverage ${ }^{[5]}$.

With the support of WHO and UNICEF, EPI program in Somalia started in 1978, with the strategy of mobile and outreach services. An evaluation of the program in 1985 showed that the strategy achieved very low immunization coverage. Between 1985 and 1988, a strategy of mass immunization campaign was adopted and implemented in major towns of the country. The operation resulted in about $75 \%$ coverage of children in towns. However, this could not be sustained and immunization coverage rapidly declined when fighting broke out in 1988. The civil war of 1988-1992 devastated the health infrastructure and dispersed health workers. The modest gains of the program were completely lost due to the war ${ }^{[6]}$. By the end of 1992, the international community, led by UNICEF, gave priority to the initiation of EPI services; and in 1996, more than $100 \mathrm{MCH}$ centers and 4 zonal cold stores were functioning ${ }^{[7]}$. The trend of low childhood immunization coverage was evident during the baseline survey conducted in Nov 2017 where we accessed the immunization coverage for the four basic vaccines namely BCG (57\%), Measles (47\%), Polio (14\%), and Pentavalent (28\%) vaccines in 9 districts i.e. Kismayo, Adado, Afmadow, Iskushuban, Armo, Alula, Bosaso, Barga and Ufayn ${ }^{[8]}$. UNICEF, 2010 reported that the immunization coverage of under five children in Mogadishu was $40 \%{ }^{[9]}$.

The Federal government, its member states and communities with help from international and local agencies established numerous mother and child health care centres which provide immunization services. However, unlike many other developing countries the immunization coverage of Somalia is still relatively very low. Thus, this study aimed to find out barriers for full immunization coverage among under five years children in Mogadishu, Somalia.

\section{Methods}

\subsection{Study Design and setting}

A community based cross-sectional study design was carried out among 820 households with one child from each household. Any Caregivers with child of 12 to 59 months lived at the selected Divisions and available at the time of data collection were considered eligible to the study. In case a single selected household has more than one eligible child, one child was selected randomly. 


\subsection{Sample Size determination}

To calculate the minimum sample size, a Cochrane formula ${ }^{[10]}$ with Design effect of 2 and $10 \%$ addition of expected non-response rate was used.

$$
\frac{Z^{2} p q}{d^{2}} * D E F F
$$

Where $\mathrm{n}=$ minimum sample size, $\mathrm{Z}=$ Standard normal deviate corresponding to $5 \%$ significant level, $\mathrm{p}=$ prevalence in previous studies (40\%) [9], $\mathrm{q}=1-\mathrm{p}, \mathrm{d}=$ precision set at 0.05 , DEFF is set at 2 . $\mathrm{Z}=1.96, \mathrm{p}=0.40, \mathrm{q}=0.60$. Appling the formula above the calculated minimum sample size was 738 . Thus, a sample size of 820 households was used in this study taking into consideration with $10 \%$ addition of expected non-response rate.

\subsection{Sampling Techniques}

A mixture of two-stage cluster sampling and systematic random sampling was used to select households. At the first stage, Mogadishu was divided into 17 districts, with each district represents a cluster, then one district (Wadajir) was selected randomly. At the second stage, the selected district was divided into four divisions in which again two divisions (Halane and Hawatako) was selected randomly, finally all households in that selected divisions was selected through systematic random sampling up to calculated sample size.

\subsection{Data collection}

Data was collected through a quantitative, pretested, structured, Researcher administered questionnaire which was initially developed in English and later translated into Somalia language. The questionnaire comprised three sections; a section on Socio-demographic variables of child's current caregiver, child and father, a section on immunization status of the child and section on the barriers affecting immunization coverage. Any household with eligible child was selected and the caregiver of that was interviewed through face to face interview. In the presence of immunization card, Information about child immunizations was collected from immunization cards or mother' $\mathrm{s}$ verbal report with the verification of the presence of a BCG scar.

\subsection{Data Analysis}

Data were entered into Statistical Package for Social Sciences (SPSS-IBM) version 20. Data entry, cleaning, processing, preliminary analysis and final write-up were done by the researchers. Frequencies and percentages were used to display immunization status of the children. Chi-square analysis was done to assess the association between dependent and independent variables. Then, all variables that showed statistical significance in the bivariate analysis, p-value $<0.2$ (Vittinghoff, Glidden, Shiboski, \& McCulloch, n.d.) were included in the multivariate logistic regression model to identify the determinants of full immunization coverage among under five years children in Mogadishu, Somalia. Adjusted Odds ratio (AOR) and their 95\% confidence intervals (CIs) were calculated from multivariate logistic regression model. A p-value $<0.05$ was considered as statistically significant. Full immunization status of the children was included in the logistic regression model as a dependent variable while socio-demographic characteristics, health centre related factors and of socio-cultural factors was used as independent variables.

\subsection{Ethical considerations}

The study protocol was reviewed and approved by the Institutional Review Board of the Jazeera University. Permission to undertake the study was obtained from the Ministry of Health, Federal Republic of Somalia. A written informed consent was obtained from the participants prior to participation in the study, and data collection was conducted confidentially.

\subsection{The following operational definitions were used}

Fully immunized/Complete immunization: An under five year child who received one dose of (Bacillus Calmette-Guerin) BCG, one dose of measles, at least three doses of DPT-HepB-Hib (pentavalent) and four doses of (Oral Polio vaccine) OPV and one dose of (Inactivated Polio Vaccine) IPV was considered to be fully immunized/complete immunization.

Not fully immunized/Incomplete immunization: An under five year child who didn't received any these five vaccines or partially received but did not 
completed all of these five vaccines was considered to be not fully immunized/Incomplete immunization.

\section{Results}

\subsection{Socio-demographic factors of the respondents}

Most of the caregivers (45.7\%) were aged 26-

35 years with the Mean \pm SD of $28.8 \pm 9.5$ years.

Majority of the caregivers $(95.5 \%)$ were female.
More than half of the caregivers $(55.6 \%)$ had no formal education while $38.6 \%$ of the fathers had at least secondary education. On employment status, majority of the responded caregivers $(74.2 \%)$ were unemployed. Majority of the children in this study were aged 12-23 months with the Mean \pm SD of $28.4 \pm 11.3$ months. $38.9 \%$ of the children in this study were first or second birth orders (Table 1)

Table 1: Socio-demographic factors of the child and caregiver

\begin{tabular}{|c|c|c|c|}
\hline Variable & Category & Frequency & Percent(\%) \\
\hline & $16-25$ & 294 & 39.7 \\
\hline & $26-35$ & 339 & 45.7 \\
\hline \multirow[t]{3}{*}{ Age of the caregiver in years } & $36-45$ & 84 & 11.3 \\
\hline & $46-55$ & 15 & 2.0 \\
\hline & $>55$ & 9 & 1.2 \\
\hline & Mean $\pm \mathrm{SD}=$ & & \\
\hline \multirow[t]{3}{*}{ Sex of caregiver } & Male & 33 & 4.5 \\
\hline & Female & 708 & 95.5 \\
\hline & Single & 15 & 2.0 \\
\hline \multirow[t]{4}{*}{ Marital status of caregiver } & Married & 614 & 82.9 \\
\hline & Divorced & 104 & 14.0 \\
\hline & Widowed & 8 & 1.1 \\
\hline & No formal education & 412 & 55.6 \\
\hline \multirow[t]{3}{*}{ Educational level of caregiver } & Primary education & 205 & 27.7 \\
\hline & Secondary and above & 124 & 16.7 \\
\hline & No formal education & 264 & 35.6 \\
\hline \multirow[t]{3}{*}{ Educational level of father } & Primary education & 191 & 25.8 \\
\hline & Secondary and above & 286 & 38.6 \\
\hline & Employed & 191 & 25.8 \\
\hline \multirow[t]{3}{*}{ Employment } & Unemployed & 550 & 74.2 \\
\hline & $<100$ & 167 & 22.5 \\
\hline & $100-300$ & 451 & 60.9 \\
\hline \multirow[t]{2}{*}{ Monthly family income in USD } & $>300$ & 123 & 16.6 \\
\hline & $12-23$ & 344 & 46.4 \\
\hline \multirow[t]{4}{*}{ Age of child in months } & $24-35$ & 249 & 33.6 \\
\hline & $36-47$ & 88 & 11.9 \\
\hline & $48-59$ & 60 & 8.1 \\
\hline & \multicolumn{2}{|c|}{ Mean $\pm \mathrm{SD}=28.4 \pm 11.3$} & \\
\hline \multirow{3}{*}{ Birth order of child } & First/second & 277 & 37.4 \\
\hline & Third/fourth & 288 & 38.9 \\
\hline & Fifth/above & 176 & 23.8 \\
\hline
\end{tabular}


3.2 Immunization Status of the children their confirmation

A total of 741caregivers of children aged under five years old were interviewed, with a response rate of $90.4 \%$. Of the total 741 children, 335(45.2\%) were fully immunized by whom $38 \%$ were confirmed by card (Table 2)

Table 2: Immunization coverage and Confirmation Method

\begin{tabular}{lccc}
\hline Vaccination Status & Frequency (\%) & By Card (\%) & Confirmation \\
& & $127(37.9)$ & $208(62.1)$ \\
\hline Fully Vaccinated & $335(45.2)$ & & \\
Not fully Vaccinated & $406(54.8)$ & & \\
\hline
\end{tabular}

\subsection{Barriers of complete Immunization}

\subsubsection{Multivariate logistic regression of socio- demographic factors and vaccination coverage}

Table 3 shows the multivariate logistic regression of socio-demographic determinants on immunization coverage. Married caregivers were 4.101 more likely to fully immunize their children then single caregivers (AOR $=4.101,95 \%$ CI: 1.062 15.835, P-value $=0.041$ ). Fathers with Secondary/above education were 1.755 times more likely to fully vaccinate their children than those with Non-formal or primary education respectively $[(\mathrm{AOR}=1.755, \quad 95 \% \quad \mathrm{CI}: \quad 1.161-2.655, \quad \mathrm{P}-$ value $=0.008$ ). Children from birth order of fifth and above were 1.539 times more likely to be fully immunized than those from first and second birth orders. $\quad(\mathrm{AOR}=1.539,95 \%$ CI: $1.011-2.343, \mathrm{P}-$ value $=0.044$ ). For additional one unit increase in Household monthly income, there was an increase in vaccination coverage of the children by a factor of 0.003 ( $\beta=0.003$, P-value $=0.001)$. Young children were more likely to be fully vaccinated than older children $(\beta=-0.018, \mathrm{P}$-value $=0.011)$. Younger caregivers were more likely to fully vaccinate their children than older caregivers $(\beta=-$ 0.024 , P-value $=0.019$ ).

\subsubsection{Multivariate logistic regression of health centres related determinants and immunization coverage}

As Table 4 shown, Availability of vaccine at the time of visit to the health centre, affordability of vaccine related cost and being born at health facility were found to be health centres related determinants on immunization coverage [(AOR $=6.118,95 \%$ $\mathrm{CI}=1.931-19.381, \quad \mathrm{P}$-value $=0.002), \quad(\mathrm{AOR}=1.938$, $95 \% \mathrm{CI}=1.230-3.053, \mathrm{P}$-value $=0.004),(\mathrm{AOR}=1.519$, $95 \%$ CI $=1.105-2.088$, P-value $=0.010)]$.

\subsubsection{Multivariate logistic regression of socio- cultural factors and immunization coverage}

As in Table 5, the Multivariate logistic regression shoed that caregivers' good knowledge, good practice and positive perception on child immunization were positively related to child immunization. For additional one unit in caregivers' knowledge increase the immunization coverage of children by a factor of 0.117 ( $\beta=0.117$, Pvalue $=0.001$ ). Likewise an increase in caregivers' practice on child immunization, increases the immunization coverage by 1.014 ( $\beta=1.014$, Pvalue $=0.001$ ) Caregivers with positive perception on child immunization were found to 4.976 times more likely fully immunize their children than those with negative perception on child immunization $(\mathrm{AOR}=4.976, \quad 95 \% \quad \mathrm{CI}: \quad 2.183-11.340, \quad \mathrm{P}-$ value $=0.001)$. 
Table 3: Multivariate logistic regression of socio-demographic factors and vaccination coverage

\begin{tabular}{|c|c|c|c|c|c|}
\hline \multirow[b]{2}{*}{ Variable } & \multicolumn{2}{|c|}{ Immunization Coverage } & \multirow{2}{*}{\multicolumn{2}{|c|}{$\begin{array}{c}\text { Adjusted Odds } \\
\text { Ratio 95\% CI }\end{array}$}} & \multirow[b]{2}{*}{ P-Value } \\
\hline & $\begin{array}{c}\text { Full covered } \\
(\%)\end{array}$ & $\begin{array}{c}\text { Not Fully covered } \\
(\%)\end{array}$ & & & \\
\hline \multicolumn{6}{|l|}{ Sex of caregiver } \\
\hline $\begin{array}{l}\text { Male } \\
\text { Female }\end{array}$ & $\begin{array}{c}14(4.2) \\
321(95.8)\end{array}$ & $\begin{array}{c}19(4.7) \\
387(95.3)\end{array}$ & & $\begin{array}{c}1 \\
25(0.459-2.287)\end{array}$ & 0.952 \\
\hline $\begin{array}{l}\text { Marital status of caregiver } \\
\text { Single } \\
\text { Widowed } \\
\text { Divorced } \\
\text { Married }\end{array}$ & $\begin{array}{c}3(0.9) \\
5(1.5) \\
46(13.7) \\
281(83.9)\end{array}$ & $\begin{array}{c}12(3.0) \\
3(0.7) \\
58(14.3) \\
333(82.0)\end{array}$ & & $\begin{array}{l}1 \\
12(0.797-46.839) \\
13(1.343-22.642) \\
1(1.062-15.835)^{*}\end{array}$ & $\begin{array}{l}0.081 \\
0.052 \\
0.041\end{array}$ \\
\hline $\begin{array}{c}\text { Educational level of caregiv } \\
\text { No formal education } \\
\text { Primary education } \\
\text { Secondary and above }\end{array}$ & $\begin{array}{l}169(50.4) \\
97(29.0) \\
69(20.6)\end{array}$ & $\begin{array}{c}243(59.9) \\
108(26.6) \\
55(13.5)\end{array}$ & & $\begin{array}{l}49(0.459-1.222) \\
06(0.432-1.154) \\
1\end{array}$ & $\begin{array}{l}0.248 \\
0.165\end{array}$ \\
\hline $\begin{array}{l}\text { Educational level of child's } \\
\text { Non-formal education } \\
\text { Primary education } \\
\text { Secondary and above }\end{array}$ & $\begin{array}{c}97(29.0) \\
74(22.1) \\
164(49.0)\end{array}$ & $\begin{array}{l}167(41.1) \\
117(28.8) \\
122(30.0)\end{array}$ & & $\begin{array}{c}1 \\
13(0.676-1.517) \\
55(1.161-2.655)^{*}\end{array}$ & $\begin{array}{l}0.951 \\
0.008\end{array}$ \\
\hline $\begin{array}{l}\text { Employment of caregiver } \\
\text { Employed } \\
\text { Unemployed }\end{array}$ & $\begin{array}{c}81(24.2) \\
254(75.8)\end{array}$ & $\begin{array}{l}110(27.1) \\
296(72.9)\end{array}$ & & $\begin{array}{c}23(0.566-1.198) \\
1\end{array}$ & 0.310 \\
\hline $\begin{array}{l}\text { Birth order of child } \\
\text { First/ second } \\
\text { Third/ fourth } \\
\text { Fifth/ above }\end{array}$ & $\begin{array}{l}119(35.5) \\
121(36.1) \\
95(28.4)\end{array}$ & $\begin{array}{l}158(38.9) \\
167(41.1) \\
81(20.0)\end{array}$ & & $\begin{array}{c}1 \\
83(0.690-1.400) \\
39(1.011-2.343)^{*}\end{array}$ & $\begin{array}{l}0.924 \\
0.044\end{array}$ \\
\hline Household monthly income & \multicolumn{2}{|c|}{ Mean \pm SD } & $\begin{array}{c}\boldsymbol{\beta} \\
0.003\end{array}$ & $\begin{array}{c}\text { AOR for } 95 \% \text { CI } \\
1.003(1.001-1.004)^{*}\end{array}$ & $\begin{array}{c}\text { P-Value } \\
0.001\end{array}$ \\
\hline Age of child & \multicolumn{2}{|c|}{$28.4 \pm 11.3$} & -0.018 & $0.982(0.968-0.996)^{*}$ & 0.011 \\
\hline Age of caregiver & \multicolumn{2}{|c|}{$28.8 \pm 9.5$} & -0.024 & $0.976(0.95-0.996)^{*}$ & 0.019 \\
\hline
\end{tabular}

$\boldsymbol{\beta}$ (Beta), AOR (Adjusted Odd Ratio), CI (Confidence Interval), SD (Standard Deviation)

*significant, $P$-value $<0.05$ 
Table 4: Multivariate logistic regression of health centre related factors and vaccination coverage

\begin{tabular}{|c|c|c|c|c|}
\hline \multirow[t]{2}{*}{ Variable } & \multicolumn{2}{|c|}{ Immunization Coverage } & \multirow{2}{*}{$\begin{array}{l}\text { Adjusted Odds } \\
\text { Ratio 95\% CI }\end{array}$} & \multirow[t]{2}{*}{ P-Value } \\
\hline & $\begin{array}{c}\text { Full covered } \\
(\%)\end{array}$ & $\begin{array}{c}\text { Not Fully covered } \\
(\%)\end{array}$ & & \\
\hline \multicolumn{5}{|c|}{$\begin{array}{l}\text { Distance to health center } \\
(\mathrm{n}=681)\end{array}$} \\
\hline$\leq 1 \mathrm{~km}$ & $186(62.8)$ & $252(65.5)$ & $0.784(0.561-1.096)$ & 0.155 \\
\hline$>1 \mathrm{~km}$ & $110(37.2)$ & $133(34.5)$ & 1 & \\
\hline \multicolumn{5}{|l|}{$\begin{array}{l}\text { Health care provider } \\
\text { availability }(n=719)\end{array}$} \\
\hline Yes & $331(98.8)$ & $360(88.7)$ & $1.158(0.321-4.172)$ & 0.822 \\
\hline No & $4(1.2)$ & $24(5.9)$ & 1 & \\
\hline \multicolumn{5}{|c|}{ Vaccine availability $(\mathrm{n}=718)$} \\
\hline Yes & $331(98.8)$ & $344(89.8)$ & $6.118(1.931-19.381)^{*}$ & 0.002 \\
\hline No & $4(1.2)$ & $39(10.2)$ & 1 & \\
\hline \multicolumn{5}{|c|}{ Cost affordability $(\mathrm{n}=730)$} \\
\hline Yes & $301(89.9)$ & $297(75.2)$ & $1.938(1.230-3.053)^{*}$ & 0.004 \\
\hline No & $34(10.1)$ & $98(24.8)$ & 1 & \\
\hline \multicolumn{5}{|l|}{ Vaccine acceptance } \\
\hline Yes & $329(98.2)$ & $369(90.9)$ & 1 & \\
\hline No & $6(1.8)$ & $37(9.1)$ & $0.479(0.181-1.267)$ & 0.138 \\
\hline \multicolumn{5}{|c|}{ Place of delivery of child } \\
\hline Health facility & $169(50.4)$ & $152(37.4)$ & $1.519(1.105-2.088)^{*}$ & 0.010 \\
\hline Home & $166(49.6)$ & $254(62.6)$ & 1 & \\
\hline
\end{tabular}

Table 5: Multivariate logistic regression of socio-cultural determinants and immunization coverage

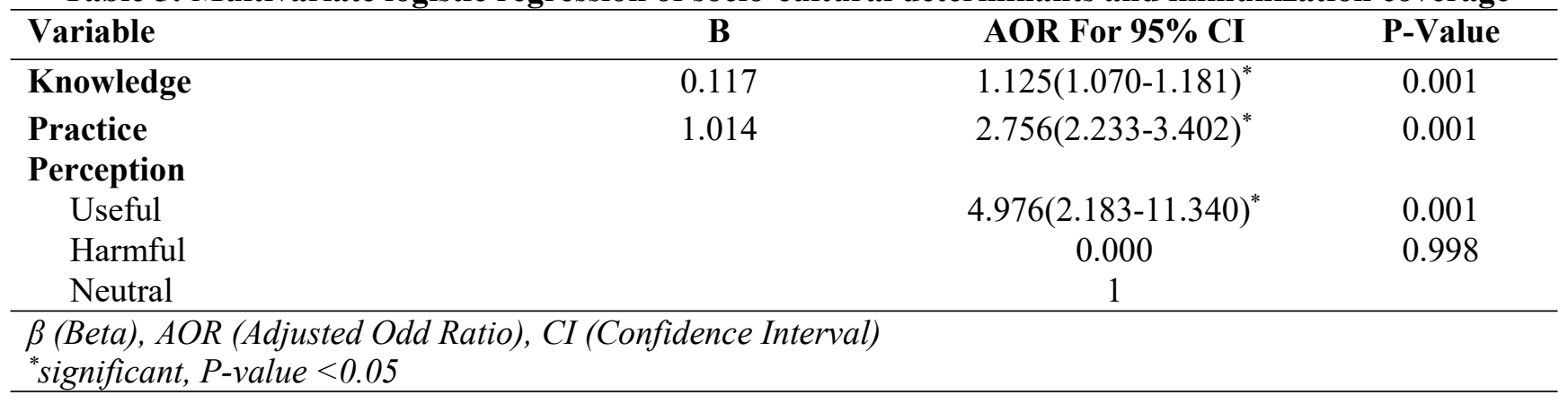

\section{Discussions}

The proportion of fully immunized children aged 12 to 59 months in Mogadishu was found to be $45.2 \%$ (335) and out of these, $37.9 \%$ (127) of them were confirmed through immunization cards and $62 \%$ were confirmed through caregiver's recall with the verification of BCG scar. This coverage is very low compared to goals of Global Immunization Vision and Strategy ${ }^{[12]}$ of at least $80 \%$ vaccination coverage in every district. The result of this study is slightly similar to previous study in Mogadishu, which reported coverage of $40 \%{ }^{[9]}$

We found that age of the caregiver had a negative significant association with immunization coverage of the children. Younger caregivers immunize their children compared to older caregivers $\quad(\beta=-0.024 ; \quad 95 \% \mathrm{CI}: \quad 0.976-0.996, \quad \mathrm{P}-$ value $=0.019)$. This finding is consistent with study conducted in Iraq [13] which found that the frequency of unvaccinated children was greater among older mothers. This disparity sends a 
positive message of little improvements on community awareness on vaccination. The study also found that educational level of the child's father was significantly associated with immunization coverage of the children. Children with fathers of secondary/above level educational were more likely to be vaccinated than those with Fathers having no formal education $(\mathrm{AOR}=1.755$; 95\% CI: 1.161-2.655, P-value $=0.008)$. Our findings are in line with studies done in Nigeria [14], Zimbabwe ${ }^{[15]}$, Ghana ${ }^{[16]}$ and Kenya ${ }^{[17]}$.This may be fathers with higher educational level were more aware of the vaccination importance than their counter parts.

This study showed that marital status had a significantly associated with child immunization completeness that is married caregivers were more likely to fully immunize their children than single caregivers $(\mathrm{AOR}=4.101 ; 95 \% \mathrm{CI}: 1.062-15.835$, Pvalue $=0.041)$. Another study in Iraq says that Marital status was significantly associated with immunization completeness, where a family with married parents were 10.4 times more likely to benefit from immunization completeness than single parents ${ }^{[13]}$

Our study also showed that there was significant positive association between monthly household income and immunization coverage of the children. For additional one unit (USD) increase in household monthly income is likely to be associated with an increase on child immunization by a factor of 0.003 on immunization coverage of the children $(\beta=0.003$; P-value $=0.001)$.

On the age of immunizing children, our study found that age of the child had a negative association with immunization coverage, That is older children were less likely to be immunized when compared to younger children $(\beta=-0.018$; Pvalue $=0.011)$. Also birth order of the child was associated with immunization coverage, fifth/above birth ordered children were more likely to be vaccinated than the first/second birth ordered once $(\mathrm{AOR}=1.539,95 \% \mathrm{CI}: 1.011-2.343$, P-value $=0.044)$. This is contradicting findings of study from Khartoum state, Sudan which showed that vaccination coverage of child increases with increase of his age ${ }^{[18]}$.

Our analysis also found that there was significant association between vaccine availability in the center at the time of visit and immunization coverage of the children. Caregivers who indicated that vaccine was available in the center by the time of their visit were six times more likely to vaccinate their children. $(\mathrm{AOR}=6.118 ; 95 \% \mathrm{CI}$ : 1.931-19.381, $\mathrm{P}$-value $=0.002$ ). our findings was supported by study in Nigeria showed that $26.2 \%$ of their studied children were not fully immunized because of unavailability of the vaccine at the health center and this was the most common reason of not completing or immunizing their children as they reported ${ }^{[19]}$. It is obvious that vaccine availability is the corner stone for vaccine coverage.

Affordability of vaccine related costs had significant association with immunization coverage of the children. Caregivers who afforded the costs were nearly two times more likely to vaccinate their children when compared to caregivers who could not afford it. (AOR=1.938; 95\% CI: 1.230-3.053, Pvalue $=0.004)$ this is consisting study from Togo that supports the notion that economic conditions influence the incompleteness of immunization coverage in children. This is probably because access to immunization services can be affected by indirect costs linked to vaccination such as the purchase of immunization records cards, transport cost or medication for vaccine-related care ${ }^{[20]}$.

In our study, place of child delivery was significantly associated with immunization coverage of the children. Children born at health facility were 1.519times more likely to be vaccinated than those born at home. $(\mathrm{AOR}=1.519$; 95\% C: 1.105-2.088, P-value=0.010). Our findings are in line with study in central Ethiopia which also showed that immunization coverage of children delivered in health facility was higher than children delivered at home ${ }^{[21]}$ and the reason behind this may be the parents get health education when the child is delivered in health facility and gets vaccination card starting with $B C G$ vaccine in the first day of live.

An increase on caregivers' knowledge on immunization was positively associated with child immunization by factor of $0.117 \quad(\beta=0.117$, Pvalue $=0.001)$. This findings was agreed by study carried out in rural setting of western Uganda, mothers with a basic understanding of the importance of childhood immunizations were more 
likely to have timely, full immunize their children compared to those with less knowledge ${ }^{[22]}$.

Caregivers who had positive perception on immunization were nearly 5 times more likely to immunize their children than those who had a neutral perception on immunization $(\mathrm{AOR}=4.976$, 95\% CI: 2.183-11.340, P-value=0.001). This results is in line with the finding from prevous study in Somalia by ${ }^{[9]}$ that showed "children's immunization status was significantly associated with caregivers' positive perceptions on the usefulness of immunizations to children"

An increase on caregivers practice on immunization coverage was found to be positively associated with child immunization by a factor of $1.014 \quad(\beta=1.014$, P-value=0.001). Two different studies conducted in Saudi Arabia ${ }^{[23]}$ and Italy [4] showed similar results to this.

This study assessed barriers for full immunization coverage among under five years children in Mogadishu, Somalia. The study relied on primary data collected by the researchers. However it has certain limitations.

The actual proportions of children who have no vaccination card were greater than those with vaccination care thus; information obtained from caregivers on the immunization status of their children is not as reliable as that of vaccination card due to recall bias. However any child with no vaccination card was checked with the BCG scar. The explanatory variables were selected based on previous studies and relied on the information available from the dataset. Therefore, there might be some other potential predictors that might be influenced by full immunisation which were not captured in this study. Beside, this study did not include qualitative method to answer the why questions. Despite the above limitations, our findings are important to understand barriers for full immunization coverage among under five years children.

\section{Conclusion}

In conclusion, the present study found that immunization coverage of under five years children in very low $(45.2 \%)$, steps to promote population awareness and community mobilization should under taken urgently. Being older and single caregivers, fathers with low educational level, low Monthly family income, child with early birth orders, child with younger age, vaccine unavailability at the health centre, vaccine related cost unaffordability, delivered at home and caregivers low knowledge, low attitude and low practice on child immunization were found to be the barriers for full immunization coverage among under five children in Mogadishu.

\section{Competing interests}

The authors declare that they have no competing interests.

\section{References}

1 Maman K, Zöllner Y, Greco D, Duru G, Sendyona S, Remy V, et al. The value of childhood combination vaccines: from beliefs to evidence. Human vaccines \& immunotherapeutics. 2015;11(9):2132-41. DOI: $\underline{10.1080 / 21645515.2015 .1044180}$

2 Control C for D, Prevention. Global routine vaccination coverage--2016. MMWR Morbidity and mortality weekly report. 2017;62(43):858.

3 Uwizihiwe JP, Bock H. 40th anniversary of introduction of Expanded Immunization Program (EPI): a literature review of introduction of new vaccines for routine childhood immunization in sub-Saharan Africa. Int J Vaccines Vaccin. 2015;1(1):4. DOI: 10.15406/ijvv.2015.01.00004

4 Sanou A, Simboro S, Kouyaté B, Dugas M, Graham J, Bibeau G. Assessment of factors associated with complete immunization coverage in children aged 12-23 months: a cross-sectional study in Nouna district, Burkina Faso. BMC International Health and Human Rights. 2017 Oct;9(S1). DOI: 10.1186/1472-698X-9-S1-S10

5 UNICEF. UNICEF Somalia - About us Immunization Equity Assessment Consultant [Internet]. 2017 [cited 2019 Dec 10]. Available from:https://www.unicef.org/somalia/about_19 $\underline{568 . h t m l}$ 

on Immunization: A Comprehensive MultiYear Plan 2011 - 2015. 2011.

7 WHO, UNICEF. WHO and UNICEF estimates of immunization coverage. 2011;122.

8 Save the Children. Strengthening demand creation for immunization. 2018;(June):1-2. Available from: https://somalia.savethechildren.net/sites/somali a.savethechildren.net/files/library/FS11

Immunization coverage.pdf

9 Mohamed A, Karanja S, Udu R. Barriers to Full Immunization Coverage of Under Five Years Children in Benadir Region, Somalia. Journal of Chemical, Biological and Physical Sciences. 2016;6(4):1-39.

10 COCHRAN W. Sampling techniques [Internet]. 2nd ed. New York: John Wiley and Sons Inc; 1963 [cited 2019 Dec 26]. Available from: https://www.coursehero.com/file/p4cchnk/CO CHRAN-W-G-1963-Sampling-techniques2nd-Ed-John-Wiley-and-Sons-Inc-New-York/

11 Save the Children. Strengthening demand creation for immunization [Internet]. 2018 [cited 2019 Dec 26]. Available from: http:/www.who.int/immunization/monitoring surveillance/who-immuniz-2015.pdf?ua=1

12 Al-Lela OQB, Bahari MB, Baderden SK, Basher AY, Kareem H. Factors Affecting on Immunization Compliance: Iraq. Journal of Pharmacy Practice and Community Medicine. 2017;3(4). DOI: 10.5530/jppcm.2017.4.67

13 Obasohan PE, Anosike BU, Etsunyakpa MB. Determinant of Full Immunization Coverage and Reasons for its Failure for Children in Bida Emirate Area, Niger State, Nigeria. Merit Research Journal of Medicine and Medical Sciences. 2015;3(10):476-83.

14 Mukungwa T. Factors associated with full immunization coverage amongst children aged 12-23 months in Zimbabwe. African Population Studies. 2015;29(2). DOI: $\underline{10.11564 / 29-2-745}$

15 Adokiya MN, Baguune B, Ndago JA. Evaluation of immunization coverage and its associated factors among children 12-23 months of age in Techiman Municipality, Ghana, 2016. Archives of Public Health.

2017;75(1):28. DOI: $10.1186 / \mathrm{s} 13690-017-$ 0196-6

16 Wanjala S. Determinants of immunization coverage in kenya. School of economics, university of nairobi; 2014.

17 Ibnouf A, Van den Borne H, Maarse J. Factors influencing immunisation coverage among children under five years of age in Khartoum State, Sudan. South African Family Practice. 2007;49(8):14-14f.

DOI: 10.1080/20786204.2007.10873611

18 Adedire EB, Ajayi I, Fawole OI, Ajumobi O, Kasasa S, Wasswa $\mathrm{P}$, et al. Immunisation coverage and its determinants among children aged 12-23 months in Atakumosa-west district, Osun State Nigeria: a cross-sectional study. BMC public health. 2016;16(1):905. DOI: 10.1186/s12889-016-3531-x

19 Landoh DE, Ouro-Kavalah FF, Yaya I, Kahn A-LL, Wasswa P, Lacle A, et al. Predictors of incomplete immunization coverage among one to five years old children in Togo. BMC public health [Internet]. 2016;16(1):968. Available from: DOI: $10.1186 / \mathrm{s} 12889-016-3625-5$

20 Etana B, Deressa W. Factors associated with complete immunization coverage in children aged 12-23 months in Ambo Woreda, Central Ethiopia. BMC public health [Internet]. 2012;12(1):566. Available from: BMC Public Health DOI: 10.1186/1471-2458-12-566

21 Vonasek BJ, Bajunirwe F, Jacobson LE, Twesigye L, Dahm J, Grant MJ, et al. Do maternal knowledge and attitudes towards childhood immunizations in rural Uganda correlate with complete childhood vaccination? PLoS ONE. 2016;11(2):1-16. DOI: 10.1371/journal.pone.0150131

22 Habib RF, Alsubhi RA, Saadawi DW, Hatim RFLAL, Saleh A, Alrashidi AA, et al. Assessment of knowledge, attitude and practice of parents towards immunization of children in Saudi Arabia, 2018. The Egyptian Journal of Hospital Medicine. 2018;71(2):2585-90.

DOI: 